\title{
Antioxidative Properties of Procyanidins B-1 and B-3 from Azuki Beans in Aqueous Systems ${ }^{\dagger}$
}

\author{
Toshiaki Ariga, Ikunori KoshiYama* and Danji Fukushima* \\ Research and Development Division, Kikkoman Corporation, \\ Noda-shi, Chiba 278, Japan \\ Received April 7, 1988
}

\begin{abstract}
Two kinds of dimeric procyanidins were isolated in pure form from azuki beans by preparative HPLC. They were identified as procyanidins B-1 and B-3, on the basis of their UV, IR FAB-MS and ${ }^{1} \mathrm{H}$-NMR spectra, and an analysis of the acid hydrolyzed products. The procyanidins were evaluated as antioxidants for linoleic acid in an aqueous linoleic acid- $\beta$-carotene model system. In the range of the tested concentrations $\left(5 \times 10^{-5} \sim 100 \times 10^{-5} \%\right)$ and $\mathrm{pH}$ values $(7 \sim 9)$, they showed remarkable antioxidative activities. Their activities were much stronger than those of such commercially available natural antioxidants as ascorbic acid, $\gamma$-oryzanol, gallic acid, L-tryptophan, (+)-catechin and $\mathrm{D}$ - $\alpha$-tocopherol. The hydrogen- or electron-donating activities of procyanidins to the DPPH radical in a $50 \%$ ethanol solution were also stronger than those of ascorbic acid and $\mathrm{D}-\alpha-$ tocopherol.
\end{abstract}

Antioxidants not only serve to extend the shelf-life of food products, but also inhibit the peroxidation of lipids in the human body. For these reasons, many investigations have been carried out and many antioxidative substances have been found. However, only a few substances among them have been approved for food use, because of their safety problems or other undesirable side effects. In the past, BHA and BHT had been used widely, before they became suspected to be responsible for liver damage. Tocopherols and ascorbic acid are naturally existing safe substances and, therefore, they have been replacing BHA and BHT rapidly, although they are weaker in their antioxidative activity than BHA and BHT.

The present studies were carried out to find more effective and safe antioxidants from natural sources. Proanthocyanidins are widely found in the plant kingdom, including food materials, but their function and physiological properties have not been revealed fully yet, mainly because of difficulties in their isolation. ${ }^{1,2)}$ We have already isolated proanthocyanidins from legume seeds, ${ }^{3 \sim 51}$ and this paper deals with antioxidative activities of dimeric procyanidins B-1 and B-3.

\section{MATERIALS AND METHODS}

Materials. $\beta$-Carotene $(99 \%)$ was purchased from Tokyo Kasei Co., and Tween-20 and (+)-catechin were obtained from Sigma Chemical Co. Linoleic acid (99\%), ascorbic acid $(99 \%)$, BHA $(99 \%)$ and all the remaining chemicals were purchased from Wako Chemical Industries. All chemicals were generally used without further purification. Distilled water was further purified before use by combined filtration through a G-10 cartridge water device (Organo Ltd.) and Mill-QSP reagent water system (Japan Milipore Ltd.). The water thus obtained was free from such metals as iron and copper, which was confirmed by the atomic absorption method.

Extraction and purification of procyanidins from azuki beans. One $\mathrm{kg}$ of fresh Japanese azuki beans (Vigna angularis Ohwi et Ohashi, var. Dainagon) was ground in a Waring blender and passed through a 12-mesh sieve. After being defatted with $n$-hexane-acetone $(1: 1)$ at $20^{\circ} \mathrm{C}$, the defatted powder was soaked in $70 \%$ aqueous acetone for $20 \mathrm{hr}$ at $20^{\circ} \mathrm{C}$, filtered and then washed. The resultant filtrates and washed solvent were combined and then saturated with $\mathrm{NaCl}$. The acetone phase was separated and washed with water saturated with $\mathrm{NaCl}$. After the

$\dagger$ Antioxidative Properties of Proanthocyanidins. Part I.

* Food Division, Kikkoman Corporation. 
acetone had been evaporated in vacuo, the residue was dissolved in an equal volume of water. The resultant aqueous solution was washed three times with diethyl ether. The aqueous phase was then saturated with $\mathrm{NaCl}$ and extracted three times with an equal volume of ethyl acetate. The resultant ethyl acetate solution was dried in vacuo at $37^{\circ} \mathrm{C}$ and then extracted with ethanol to give an ethanol solution containing oligomeric proanthocyanidins. This ethanol solution of the oligomeric proanthocyanidins was subjected to Sephadex LH-20 chromatography $(2.52 \times 70 \mathrm{~cm}$ column $)$ and eluted with ethanol, the eluate being fractionated every $10 \mathrm{ml}$ into 300 tubes. Each fraction was analyzed by TLC. ${ }^{41}$ Fractions $98 \sim$ 115 and $130 \sim 139$ were respectively combined and purified by preparative HPLC ( $\mu$ Bondapack $C_{18}, 19 \times 150$ $\left.\mathrm{mm}, 7.5 \% \mathrm{MeOH}, 30^{\circ} \mathrm{C}, 5 \mathrm{ml} / \mathrm{min}\right)$. The former combined fraction was designated as compound $\mathrm{I}(12 \mathrm{mg})$ and the latter as compound II (11 mg).

Instruments for structural elucidation. UV spectra were taken on a HITACHI 557 spectrophotometer, and IR spectra were recorded by the $\mathrm{KBr}$ disk technique on a JASCO A-202 spectrophotometer. FAB mass spectra and collision-induced dissociation spectra (CIDS) by the linked scanning method were obtained with a JEOL-100 spectrometer. ${ }^{1} \mathrm{H}-\mathrm{NMR}$ spectra were run at $200 \mathrm{MHz}$ in acetone- $d_{6}$ with a JEOL-FX 200 spectrometer.

Antioxidative assay. The assay for oxidizing activity of linoleic acid- $\beta$-carotene in an aqueous system was carried out by measuring the decrease in absorbance at $460 \mathrm{~nm}$, using a double-beam recording spectrophotometer (HITACHI 557 instrument). ${ }^{6 \sim 10)}$ The test samples contained $6.0 \mathrm{ml}$ of buffered linoleic acid- $\beta$-carotene mixture, $0.2 \mathrm{ml}$ of $0 \sim 0.040 \%$ antioxidant in $50 \%$ ethanol solution, and distilled water by which the final volume was brought to $8.0 \mathrm{ml}$. Concentrations in the initial reaction mixture were as follows: $\beta$-carotene, $1.4 \times 10^{-5} \mathrm{M}$; linoleic acid, $2 \times 10^{-3} \mathrm{M}$; Tween-20, $0.005 \%$; Tris buffer $(\mathrm{pH} 7.0)$ or citrate phosphate buffer $(\mathrm{pH} 3.0 \sim 9.0), 0.1 \mathrm{M}$. The blank sample contained all the reagents except $\beta$-carotene. The initial rate of decrease in absorbance at $460 \mathrm{~nm}$ was computed from a graphical record and converted into the rate of $\beta$-carotene decrease in $\mathrm{n} \mathrm{mol} / \mathrm{min}$. Relative antioxidative activity is expressed as the ratio of the average

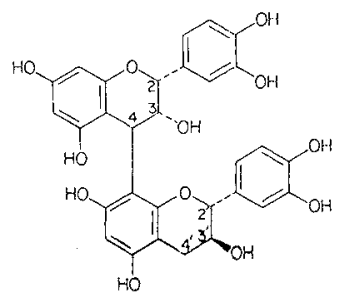

Procyanidin B-1 $\beta$-carotene destruction rate for the initial five minutes with the control to that with the samples throughout this work. According to the definition, the antioxidative activity of the control (no antioxidant added) was calculated as the value 1.00 , an antioxidant having a value over 1.00 , while a prooxidant had a value from 0 to 1.00 . The hydrogendonating activity was estimated according to the method of Kirigaya et al. ${ }^{11}$

\section{RESULTS AND DISCUSSION}

\section{Identification of procyanidins $B-1$ and $B-3$}

Both compounds I and II were hydrolyzed into cyanidin and $(+)$-catechin by acid. ${ }^{41}$ The UV spectra of compounds I and II were similar to those of $(+)$-catechin or ( -$)$-epicatechin, and showed an absorption maximum at $280 \mathrm{~nm}$ in an ethanol solution. The IR spectra of these compounds were also similar to those of $(+)$-catechin or (-)-epicatechin. There was an $\mathrm{MH}^{+}$ion peak at $m / z 579$ on the FAB mass spectrum of compound $I$, and this peak was further analyzed by the linked scanning method to obtain a collision-induced dissociation spectrum. In the CIDS spectrum, there were peaks at $578,560,427,409,289,275$ and 247 , which are characteristic of a dimeric structure. There was no essential difference between compounds I and II on the FAB-MS and CIDS spectra.

However, the ${ }^{1} \mathrm{H}-\mathrm{NMR}$ spectra were different between the two, the ${ }^{1} \mathrm{H}-\mathrm{NMR}$ spectrum for compound I showing the following $\delta$ values and coupling constants: $2.40 \sim$ $3.10\left(2 \mathrm{H}, \mathrm{d}, \mathrm{d}, \mathrm{H}-4^{\prime}\right), 3.54 \sim 3.62(2 \mathrm{H}, \mathrm{m}, \mathrm{OH}-$ $\left.3,3^{\prime}\right), 3.98(1 \mathrm{H}, \mathrm{m}, \mathrm{H}-3), 4.05\left(1 \mathrm{H}, \mathrm{m}, \mathrm{H}-3^{\prime}\right)$, $4.69(1 \mathrm{H}, \mathrm{d}, J=2, \mathrm{H}-4), 4.79(1 \mathrm{H}, \mathrm{d} ; J=8$, $\left.\mathrm{H}-2^{\prime}\right), 5.09(1 \mathrm{H}, \mathrm{s}, \mathrm{H}-2), 5.95\left(2 \mathrm{H}, \mathrm{d}, \mathrm{H}-6,6^{\prime}\right)$, $6.02(1 \mathrm{H}, \mathrm{d}, \mathrm{H}-8), 6.5 \sim 7.1(6 \mathrm{H}, \mathrm{m}, \mathrm{ArH})$,

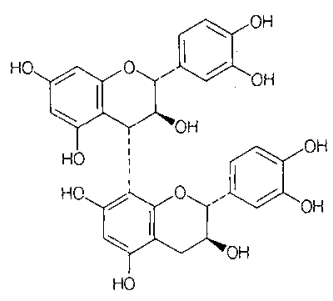

Procyanidin $\mathrm{B}-3$

Fig. 1. Structures of Dimeric Procyanidins Isolated from Azuki Beans. 
and $7.3 \sim 8.3(8 \mathrm{H}, \mathrm{m}, \mathrm{ArOH})$. These chemical shifts and coupling constants were identical with those of procyanidin B-1, which was isolated from mountain cranberries (Vaccinium vitis-idaea) by Nonaka et al. ${ }^{12)}$ On ther other hand, the ${ }^{1} \mathrm{H}-\mathrm{NMR}$ spectrum for compound II showed the following $\delta$ values and coupling constants: $2.58 \sim 2.95\left(2 \mathrm{H}, \mathrm{d}, \mathrm{d}, \mathrm{H}-4^{\prime}\right)$, $3.72 \sim 3.83\left(2 \mathrm{H}, \mathrm{m}, \mathrm{OH}-3,3^{\prime}\right), 4.08(1 \mathrm{H}, \mathrm{m}$, $\left.\mathrm{H}-3^{\prime}\right), 4.32(1 \mathrm{H}, \mathrm{d}, J=9.5, \mathrm{H}-4), 4.26 \sim 4.54$ $(1 \mathrm{H}, \mathrm{m}, \mathrm{H}-3), 4.55\left(1 \mathrm{H}, \mathrm{d}, J=3.5, \mathrm{H}-2^{\prime}\right), 4.73$ $(1 \mathrm{H}, \mathrm{d}, J=8.0, \mathrm{H}-2), 5.8 \sim 7.1(9 \mathrm{H}, \mathrm{m}, \mathrm{ArH})$, and $7.2 \sim 8.5(8 \mathrm{H}, \mathrm{m}, \mathrm{ArOH})$. These data are in agreement with those for procyanidin B-3, which was isolated from rhubarb (Rhei rhizoma) by Jacques et al. ${ }^{13)}$

It is now clear that the compounds $I$ and II were identical with procyanidin B-1 and procyanidin $\mathrm{B}-3$, respectively, on the basis of their UV, IR, ${ }^{1} \mathrm{H}-\mathrm{NMR}, \mathrm{FAB}-\mathrm{MS}$ and CIDS spectra and by analysis of the acid hydrolyzed products. This is the first report that describes the stereochemical structure of proanthocyanidins contained in legume seeds including azuki beans.

\section{Antioxidative properties of procyanidins $B-1$ and $B-3$}

An antioxidative assay was carried out by measuring the rate of $\beta$-carotene bleaching in the coupled oxidation of linoleic acid and $\beta$ carotene in the present work, the $\beta$-carotene bleaching or destruction indicating the oxidation of linoleic acid. This technique has the advantage that the initial velocity of $\beta$-carotene bleaching can be determined accurately in a short time with a small sample amount, although careful attention, particularly to the purity of water and to oxidation during the evaporation of the $\beta$-carotene solution, was required in order to obtain reproducible values. In this work, pure water free from metals was used, and $\beta$-carotene containing chloroform was evaporated at $30 \sim 32^{\circ} \mathrm{C}$ under reduced pressure to establish reproducible averages. The linoleic acid- $\beta$-carotene oxidizing activity was assayed 5 times at $20^{\circ} \mathrm{C}$ for each sample, while the hydrogen-donating activity was estimated 3 times at $25^{\circ} \mathrm{C}$ for each sample.

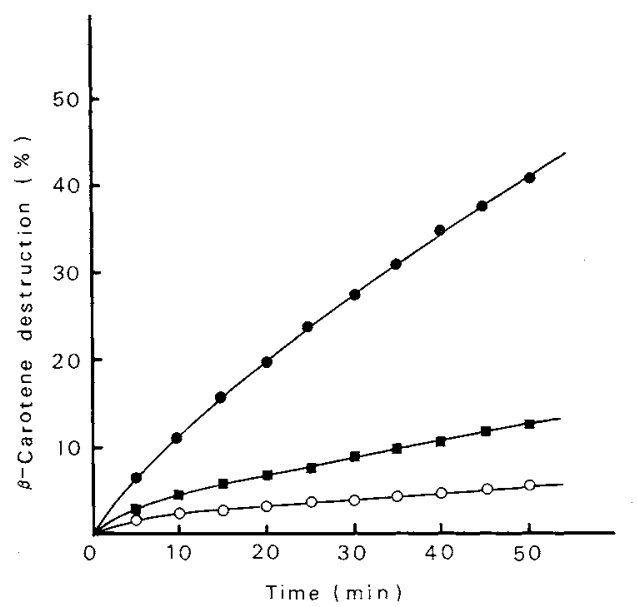

Fig. 2. Time Courses for the $\beta$-Carotene Destruction Rate of Procyanidin B-3 and $\alpha$-Tocopherol at $\mathrm{pH} 7.0$.

- control; $\square$, $\alpha$-tocopherol $\left(50 \times 10^{-5 \%}\right) ; 0$, procyanidin B-3 $\left(50 \times 10^{-5 \%}\right)$.

Table 1. Effect of Procyanidin B-3 and $\alpha$-Tocopherol Concentration on $\beta$-Carotene Destruction at pH 7.0

\begin{tabular}{ccccc}
$\begin{array}{c}\text { Concentration } \\
\text { in an aqueous } \\
\text { system (\%) }\end{array}$ & $\begin{array}{c}\beta \text {-Carotene destruction } \\
(\mathrm{nmol} / \mathrm{min})\end{array}$ & $\begin{array}{c}\text { R-Tocopherol } \\
\text { Procyanidin B-3 }\end{array}$ & $\begin{array}{c}\text { Relative antioxidative } \\
\text { activity }^{a}\end{array}$ \\
\hline 0 (control) & 0.507 & 0.507 & 1.00 & 1.00 \\
$5 \times 10^{-5}$ & 0.200 & 0.367 & 2.54 & 1.38 \\
$10 \times 10^{-5}$ & 0.197 & 0.336 & 2.58 & 1.51 \\
$25 \times 10^{-5}$ & 0.156 & 0.256 & 3.24 & 1.98 \\
$50 \times 10^{-5}$ & 0.126 & 0.234 & 4.01 & 2.17 \\
$100 \times 10^{-5}$ & 0.083 & 0.175 & 6.08 & 2.90
\end{tabular}

\footnotetext{
a Ratio of control to sample at the rate of $\beta$-carotene destruction.
} 
Table II. Effect of pH on the Antroxidative Activities of Procyanidin B-3 and $\alpha$-TOCOPHEROL AT THE CONCENTRATION OF $50 \times 10^{-5} \%$

\begin{tabular}{ccccccc}
\hline & \multicolumn{3}{c}{$\beta$-Carotene destruction $(\mathrm{nmol} / \mathrm{min})$} & & \multicolumn{2}{c}{ Relative antioxidative activity } \\
& Control & Procyanidin B-3 & $\alpha$-Tocopherol & & Procyanidin B-3 & $\alpha$-Tocopherol \\
\hline 3 & 0.305 & 0.277 & 0.292 & & 1.10 & 1.05 \\
4 & 0.414 & 0.370 & 0.383 & & 1.12 & 1.08 \\
5 & 0.470 & 0.423 & 0.427 & & 1.11 & 1.10 \\
6 & 0.592 & 0.515 & 0.495 & & 1.15 & 1.20 \\
7 & 0.507 & 0.126 & 0.233 & & 4.01 & 2.17 \\
8 & 0.161 & 0.013 & 0.065 & & 12.02 & 2.48 \\
9 & 0.177 & 0.028 & 0.096 & & 6.24 & 1.85 \\
\hline
\end{tabular}

The time courses for $\beta$-carotene destruction in the aqueous system are illustrated in Fig. 2, where it can be seen that the antioxidative activity of procyanidin B-3 at the concentration of $5 \times 10^{-4 \%} \%(\mathrm{w} / \mathrm{v})$ was superior to that of $\alpha$-tocopherol. From the behavior of the three curves in Fig. 2, it is obvious that a comparison of the antioxidative activities can be made by measuring the average velocity of $\beta$-carotene destruction for only the first five minutes as an indication of the oxidative power of linoleic acid. Table I shows that procyanidin B-3 was more efficient than $\alpha$ tocopherol at an addition of $5 \times 10^{-5}$ to $100 \times 10^{-5 \%}$, and that its relative antioxidative activity increased markedly with increasing concentration. In Table I, $50 \times 10^{-5 \%}$ in the aqueous system corresponds to $0.89 \%$ of linoleic acid contained in the system.

Only a few workers have paid attention to the effect of $\mathrm{pH}$ on the antioxidative activity of antioxidants, but the effect of $\mathrm{pH}$ on the antioxidative activity of antioxidants, but the effect of $\mathrm{pH}$ is very important, because there are many foods and animal organisms which are different in $\mathrm{pH}$ value. Table II shows the effect of $\mathrm{pH}$ on the antioxidative activities of procyanidin B-3 and $\alpha$-tocopherol. According to this table, procyanidin B-3 was much stronger than $\alpha$-tocopherol in its antioxidative power in the neutral and weakly alkaline region $(\mathrm{pH} 7 \sim 9$ ). The maximum value for the relative antioxidative activity of procyanidin $\mathrm{B}-3$ was 12.02 at $\mathrm{pH} 8$, whereas the maximum value for $\alpha$-tocopherol was 2.17 at $\mathrm{pH}$ 8. The

Table III. Comparison of the Antioxidative Activities among Procyanidins and Commercially Available Natural Antioxidants in an Aqueous MODEL SySTEM

\begin{tabular}{|c|c|c|}
\hline Natural compound & $\begin{array}{l}\beta \text {-Carotene } \\
\text { destruction } \\
(\mathrm{nmol} / \mathrm{min})\end{array}$ & $\begin{array}{c}\text { Relative } \\
\text { antioxidative } \\
\text { activity }\end{array}$ \\
\hline
\end{tabular}

$$
\left(50 \times 10^{-5 \%}\right)
$$

Procyanidin B-1

Procyanidin B-3

L-Ascorbic acid

Gallic acid

L-Tryptophan

$(+)$-Catechin

D- $\alpha$-Tocopherol

$$
\left(1 \times 10^{-5} \mathrm{M}\right)
$$

Procyanidin B-1

Procyanidin B-3

L-Ascorbic acid

Gallic acid

L-Tryptophan

(t)-Catechin

D- $\alpha$-Tocopherol

$\begin{array}{ll}0.126 & 4.02 \\ 0.126 & 4.01 \\ 1.334 & 0.38 \\ 0.478 & 1.06 \\ 0.433 & 1.17 \\ 0.203 & 2.50 \\ 0.234 & 2.17 \\ & \\ 0.117 & 4.33 \\ 0.118 & 4.29 \\ 1.584 & 0.32 \\ 0.483 & 1.05 \\ 0.453 & 1.12 \\ 0.229 & 2.21 \\ 0.250 & 2.03\end{array}$

oxidation rate of the control also depended on pH. Table III shows a comparison of the relative antioxidant activities among dimeric procyanidins (procyanidins B-1 and B-3) and well-known natural antioxidants in the aqueous model system. The antioxidative activity of procyanidin B-1 was nearly equal to that of procyanidin B-3. Procyanidins B-1 and B-3 were much stronger than such commercial natural antioxidants as ascorbic acid, $\gamma$-oryzanol, gallic acid, L-tryptophan, (+)-catechin and $\alpha$-tocopherol in their antioxidative power 


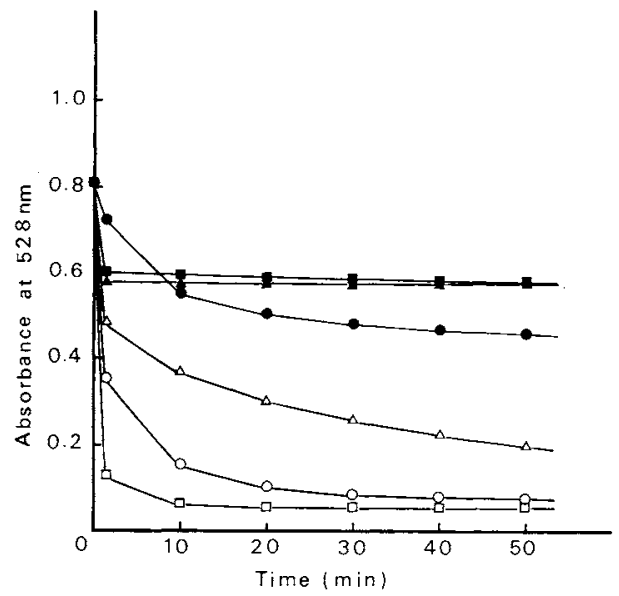

FIG. 3. Hydrogen-donating Activities of Procyanidins and Antioxidants to DPPH (1,1-diphenyl-2-picrylhydrazyl) at the Concentration of $1 \times 10^{-5} \mathrm{M}$ in $50 \% \mathrm{EtOH}$.

- BHA; $\boldsymbol{\square}$, ascorbic acid; $\boldsymbol{\Delta}, \boldsymbol{\alpha}$-tocopherol; $\bigcirc$, procyanidin B-3; $\square$, procyanidin B-1; $\triangle,(+)$-catechin.

in the aqueous system. It was observed in the present model system that ascorbic acid at the concentration of $50 \times 10^{-5 \%} \%(\mathrm{w} / \mathrm{v})$ acted not as an antioxidant, but as a prooxidant. This action of ascorbic acid was reproducible under the conditions used. Kanner has observed that ascorbic acid possessed a prooxidant action, which was influenced by the concentration (below $10^{-2} \mathrm{M}$ ), the presence of metal ions, lipid peroxides and water, and by other factors. ${ }^{8)}$

Figure 3 illustrates the hydrogen- or electron-donating activities of the antioxidants, which were assayed by their reaction with DPPH (1,1-diphenyl-2-picrylhydrazyl), which is a stable radical. When a radical inhibitor such as BHA is mixed with DPPH, it donates $\mathrm{H}^{+}$to DPPH, resulting in the decolorization of DPPH at a slow rate. On the other hand, when a reductone such as ascorbic acid is mixed with DPPH, it decolorizes DPPH by its reducing power at a very rapid rate, the reaction between reductone and DPPH terminating within one minute. ${ }^{11}$ Figure 3 shows that the hydrogen-donating rates of procyanidins B-1 and B-3 to DPPH were similar to that of BHA, but different from that of ascorbic acid. Furthermore, the hydrogen- donating activity of procyanidin B-3 after 50 min was greater than that of ascorbic acid and $\alpha$-tocopherol, indicating that dimeric procyanidins are good hydrogen donators. This suggests the possibility that dimeric procyanidins may act a radical inhibitor.

As shown in Fig. 1, procyanidins B-1 and B3 have electron-rich hydroxyl moieties such as eight phenolic hydroxyl groups, two aliphatic hydroxyl groups and conjugated double bonds. Eight phenolic hydroxyl groups act as hydrogen donators and contribute to the antioxidative properties of dimeric procyanidins. Two aliphatic hydroxyl groups may perhaps take part in the solubility of dimeric procyanidins in water, and conjugated double bonds in aryl groups stabilize the electrons in the molecule. These characteristics of the molecular structures suggested to us the antioxidative properties of dimeric procyanidins in aqueous systems. Despite that, it still remains unknown why dimeric procyanidins were stronger than monomeric catechin in their antioxidative power. We speculate on the fact that: the solubility of an antioxidant is one of the factors responsible for its antioxidative activity, dimeric procyanidin B-3 being much more soluble in water than monomeric catechin. This coincides with the result that a dimer was more active than a monomer in aqueous systems. But that does not seem to be all. We are now further studying the mechanism.

Of the known proanthocyanidins, dimeric procyanidin B-types are known to be the most widely distributed in food materials. $\mathrm{Hu}-$ mans take many of the dimeric procyanidin B-types through such foods as apples, ${ }^{13)}$ cran apples, ${ }^{13)}$ strawberries, ${ }^{13)}$ cranberries, ${ }^{13)}$ barleys, ${ }^{14)}$ beers, ${ }^{15)}$ ciders, ${ }^{16)}$ and so on. For example, apples contain dimeric procyanidin B- 1 in the concentration of $0.05 \sim 0.10 \%$, and strawberries contain procyanidin B-3 in the concentration of $0.10 \sim 0.50 \%$. Several reports have suggested that lipid peroxidation may lead to destabilization and disintegration of cell membranes, to liver injury and other diseases, and finally, to aging and suscepti- 
bility to cancer. ${ }^{17 \sim 18)}$ D. Harman reported that the addition of 2-MEA or BHT to feed extended the life span of mice and rats. ${ }^{19}$ ) D. Harman also reported that free radical reactions usually occur in blood. ${ }^{20)}$ The aqueous model system we used was close to 10 fold human blood diluted with water in the concentration of lipids, ${ }^{21}$ in the evolution level of lipid peroxides, ${ }^{22)}$ in $\mathrm{pH}$, and in the phase (a kind of $\mathrm{O} / \mathrm{W}$ emulsion). Dimeric procyanidins taken into a body through foods might act as antioxidants in human blood. It is of interest to what extent dimeric procyanidins inhibit the production of lipid peroxides in human blood.

In conclusion, the antioxidative activities of procyanidins B-1 and B-3 in an aqueous model system were much stronger than those of $\alpha$ tocopherol across the broad range of concentrations used and in the optimum $\mathrm{pH}$ range of 7 to 9 .

Acknowledgments. The authors express their thanks to Professor H. Kato, Associate Professor S. Arai and Dr. M. Watanabe of the University of Tokyo for their valuable suggestions, and to Dr. Y. Niwa of National Chemical Laboratory for Industry for MS measurements. The authors are also indebted to Dr. M. Nagasawa, Dr. F. Ono, Dr. H. Hashimoto and Dr. M. Hamano of the Kikkoman corporation for their discussions and encouragement, and to Miss $\mathrm{C}$. Tobe for her technical assistance.

\section{REFERENCES}

1) I. Nishioka, Yakugaku Zasshi, 103, 125 (1983).

2) I. Nishioka, Kagaku to Seibutsu, 24, 428 (1986).

3) T. Ariga, Y. Asao, H. Sugimoto and T. Yokotsuka, Agric. Biol. Chem., 45, 2705 (1981).
4) T. Ariga and Y. Asao, Agric. Biol. Chem., 45, 2709 (1981).

5) T. Ariga, Abstracts of Papers, the Annual Meeting of the Agricultural Chemical Society of Japan, Sapporo, July, 1985, p. 282.

6) A. Ben-Aziz, S. Grossman, I. Ascarelli and P. Budowski, Analytical Chemistry, 34, 88 (1970).

7) A. Ben-Aziz, S. Grossman, I. Ascarelli and P. Budowski, Phytochemistry, 10, 1445 (1971).

8) J. Kanner and H. Mendel, J. Food Sci., 41, 183 (1976).

9) P. A. Hammerschmidt and D. E. Pratt, J. Food Sci., 43, 556 (1978).

10) J. Kanner, S. Harel, J. Shagalovich and S. Berman, Agric. Food Chem., 32, 512 (1984).

11) N. Kirigaya, H. Kato and M. Fujimaki, Nippon Nōgeikagaku Kaishi, 45, 292 (1971).

12) G. Nonaka, I. Nishioka, T. Nagasawa and H. Oura, Chem. Pham. Bull., 29, 2862 (1981).

13) R. S. Thompson, D. Jacques, E. Haslam and R. J. N. Janner, J. Chem. Soc., Perkin I, 11, 1387 (1972).

14) I. McMurrough, M. J. Loughrey and G. P. Hennigan, J. Sci. Food Agric., 34, 62 (1983).

15) R. Vancraenenbroeck, H. Gorissen and R. Lontie, Proceedings of the European Brewery Convention, Amsterdam, 1977, p. $429 \sim 439$.

16) A. G. H. Lea and C. F. Timberlake, J. Sci. Food Agric., 25, 1537 (1983).

17) T. Player, in "Free Radicals, Lipid Peroxidation and Cancer," ed. by D. C. H. McBrien and T. F. Slater, Academic Press, London, 1982, p. 173.

18) T. Osawa, A. Ide, J. D. Su and M. Namiki, J. Agric. Food Chem., 35, 808 (1987).

19) D. Harman, Age, 1, 145 (1978).

20) D. Harman and L. H. Diette, J. Gerontol, 21, 560 (1966).

21) H. Kobayashi, in "Medical Technology," ed. by Editorial Committee of Medical Technology, Ishiyaku Publishers, Inc., Tokyo, 1980, pp. 1004 1007.

22) K. Yagi, in "Medical Technology," ed. by Editorial Committee of Medical Technology, Ishiyaku Publishers, Inc., Tokyo, 1980, pp. 1080 1082. 